Review Article

\section{Child neglect - still a neglected problem in the global world: A review}

\section{Björn Tingberg ${ }^{1}$ and Doris Nilsson ${ }^{2 *}$}

'Education Unit for Children's and Adolescent's Health, Department of Women's and Children's Health, Karolinska Institute, Sweden

${ }^{2}$ Institution of Behavioral Sciences and Learning, Department psychology, Linköping University, Linköping, Sweden

\section{Summary}

Child neglect is a global problem that involves large costs for both the individual and for society. This article is based on published reviews and meta-analyses in the field of child neglect between 1980 and 2018. Of a total of 433 articles, 13 was included, main Data bases has been PubMed, Scopus, Web of Science, Psych Info, ERIC, CINAHL. The prevalence in the normal population was found to be between 16 and 26 percent, while the prevalence in clinical groups seem to be significantly higher. For example, was the prevalence of neglect $50 \%$ among patients with eating disorder. It is especially important to know who is reporting neglect. Research shows that neglect is strongly associated with among other things, depression, one of the most common illnesses among the general public. The theoretical models that are used are ecological. Risk factors can be found at all levels when using ecological models. Research shows that factors involving the relationship parent-child are among the most important. Neglect is more common in low-income countries than in high income countries.

Most studies point to the importance of prevention. Existing preventive programs are most often of family and parental character.

More research is needed, especially as concerns the development of preventive programs that can identify specific types of neglect and present suitable preventive measures, both at the societal and family level.

\section{Key points}

1. Neglect is a global problem.

2. Prevalence depends on the measurement method and can vary between about $16 \%$ and $76 \%$.

3. Prevalence is higher when negligence is self-reported than when reported by professionals.

4. The most common and most serious risk factors are present in the microsystem. Parenting and interactions between child and parent are considered important.

5. There is a link between neglect and, above all, depression, but also anxiety, self-harm and eating disorders.

\section{More Information}

*Address for Correspondence: Doris Nilsson, Institution of Behavioral Sciences and Learning, Department psychology, Linköping University, Linköping, Sweden, Tel: 46-13 284429; Email: doris.nilsson@liu.se

Submitted: 16 September 2020

Approved: 28 September 2020

Published: 29 September 2020

How to cite this article: Tingberg B, Nilsson D. Child neglect - still a neglected problem in the global world: A review. J Adv Pediatr Child Health. 2020; 3: 038-046.

DOI: 10.29328/journal.japch.1001016 ORCiD: orcid.org/0000-0002-7796-0873

Copyright: @ 2020 Tingberg B, et al. This is an open access article distributed under the Creative Commons Attribution License, which permits unrestricted use, distribution, and reproduction in any medium, provided the original work is properly cited.

Keywords: Child neglect; Child abuse; Mental health; Prevalence; Risk factors

\section{Check for updates}

\section{Introduction}

The concept child maltreatment can be seen as an umbrella concept, and neglect is one way for children to be hurt. Neglect can be divided into several distinct subgroups [1]:

- Physical neglect.
- Emotional neglect.

- Medical neglect.

- Neglect of psychological health.

- Educational neglect. 
Neglect also has to do with a lack of supervision, or that responsible adults do not see to it that a child is given adequate food, living space, clothes, education, or basic health care. It can also have to do with a lack of emotional support and love, chronic inattention to the child, caregivers who are psychologically or mentally inaccessible as indicated by failure to observe signs and signals, or that the child is exposed to the effects of adults' abuse of narcotics or alcohol [1,2].

In contrast with other types of abuse, neglect is a matter of the absence of things, an omission of care that the child needs [2]. We know that neglect can appear in many different forms and can result in a variety of both short-term and long-term consequences [3].

Several organisations such as WHO and UN (UNICEF) report that neglect is a global problem that results in extensive suffering for the individual and even in large-scale costs for society. Many researchers take as their starting point the WHO's definition from 1999 that includes neglect and also has to do with organisations including schools and health care institute and even society at all levels from village to city and a failure to recognize children's fundamental needs and failure to support or aid children who are in need of help. According to many researchers, the greatest challenge faced by professionals who meet children in their profession is to find the most appropriate boundaries between sufficiently satisfactory (good-enough) parenting and neglect [3]. To map the extent of neglect, prevalence, risk factors, costs, and possible interventions, it is necessary to be able to identify where neglect is present and what it looks like in a specific setting. For this purpose, different scales have been used and, the Childhood Trauma Questionnaire (CTQ) and Adverse Childhood experience (ACE) are common instruments. Woodman and colleagues [4] showed that it was very difficult to identify neglected children among a larger group, for example at an emergency care unit. They were unable to find a satisfactory and secure method for screening a population to identify neglected children [4].

Research on the prevalence of neglect displays varied results and outcomes depending on how a study is designed and carried out [5]. The economy of a country, the groups chosen for a study, and how the study is carried out (measuring instruments, interviews, or other means) strongly affect the results [5]. Twenty-six percent of children in a normal population experience neglect at some time during their lives [5]. This may be compared with the finding that approximately $10 \%$ have been exposed to sexual abuse, and almost $22 \%$ have been exposed to physical violence [5].

There are many risk factors for neglect, and often there are several that interact. Risk factors are to be found at every level in the ecological system at the family and/or societal level. Research places poor psychological health in parents in a prominent place, and violence among closely related family or group members, and even the child's own problems as risk factors at the family/individual level. Risk factors that have shown to be important at the societal level can be poverty, dangerous or insecure living areas, and few possibilities for recreation [6].

What is known is that to be neglected results in an increased risk for several difficult effects both short and long term [3]. Many researchers emphasize that it is an equally serious problem to be neglected as it is to be subject to physical or sexual abuse [2,3,7-9].

The consequences of neglect can be quite different depending on the particular type of neglect in question. There is a difference between not getting enough food and not being given sufficient love, both are "dangerous" but have completely different consequences both short and long term. Neglect is therefore to be seen as extremely heterogeneous $[2,3,7]$.

Concerning prevention it has been found that programs of early home visits have a desirable effect [10].

\section{Aim}

The aim of this study was to investigate how neglect has been handled in research up to now, globally and to review findings on definitions, prevalence, risk, consequences, prevention, and costs to the individual and to society.

\section{Method}

Given the breadth and depth of this field, we have chosen in this review to examine only review and meta-analysis studies. The field is quite broad and has not been so clearly researched in the sense that child neglect has not been the specific goal of studies but rather that child neglect is often examined as just one form of child mistreatment.

This article is based on a systematic review of the literature published between 1988 up to Dec. 2018.

Search terms: Review, reviews, meta-analysis, prevalence or incidence, neglect, infant, child, adolescent, teenager, pediatric, child neglect, emotional neglect, educational neglect, fatal neglect, supervisory neglect, physical neglect,

Data bases: PubMed, Scopus, Web of Science, PsychInfo, ERIC, CINAHL

The total number of hits was 428 after duplicates had been removed. An additional 269 articles were sampled, the abstract read, and in the case of uncertainty sometimes the article was read in its entirety by both researchers.

An additional 63 articles were identified by examination of lists of references and journals such as Child Abuse \& Neglect" and of these, five were included in our study. 
Inclusion criteria have been that the studies were review studies of empirical research where neglect was treated in at least a part of the review.

Exclusion criteria were that the studies were only based on the literature and that neglect was not considered or had been seen as one of many kinds of mistreatment of children.

Both authors have each read all the abstracts in all the articles. The authors then independently passed judgement on the abstract and dismissed articles that were not compatible with the criteria for inclusion and were thus excluded as not being essential for this review. The included reviews in this study have been evaluated according to AMSTAR concerning usefulness and bias [11] and shown in table 1. The level of agreement between both authors on which articles were to be part of the review was $95 \%$. In cases where we engaged in discussion, we were able to reach a consensus view. The final result was that we reached complete agreement on which articles were to be included in this review of existing knowledge (Figure 1).

\section{Results}

The studies included in this review can be seen in table 1, they differ in such a way that some are metanalyses and some are reviews and have different focus concerning neglect, such as, prevalence, societal costs, consequences, risk factors and prevention.

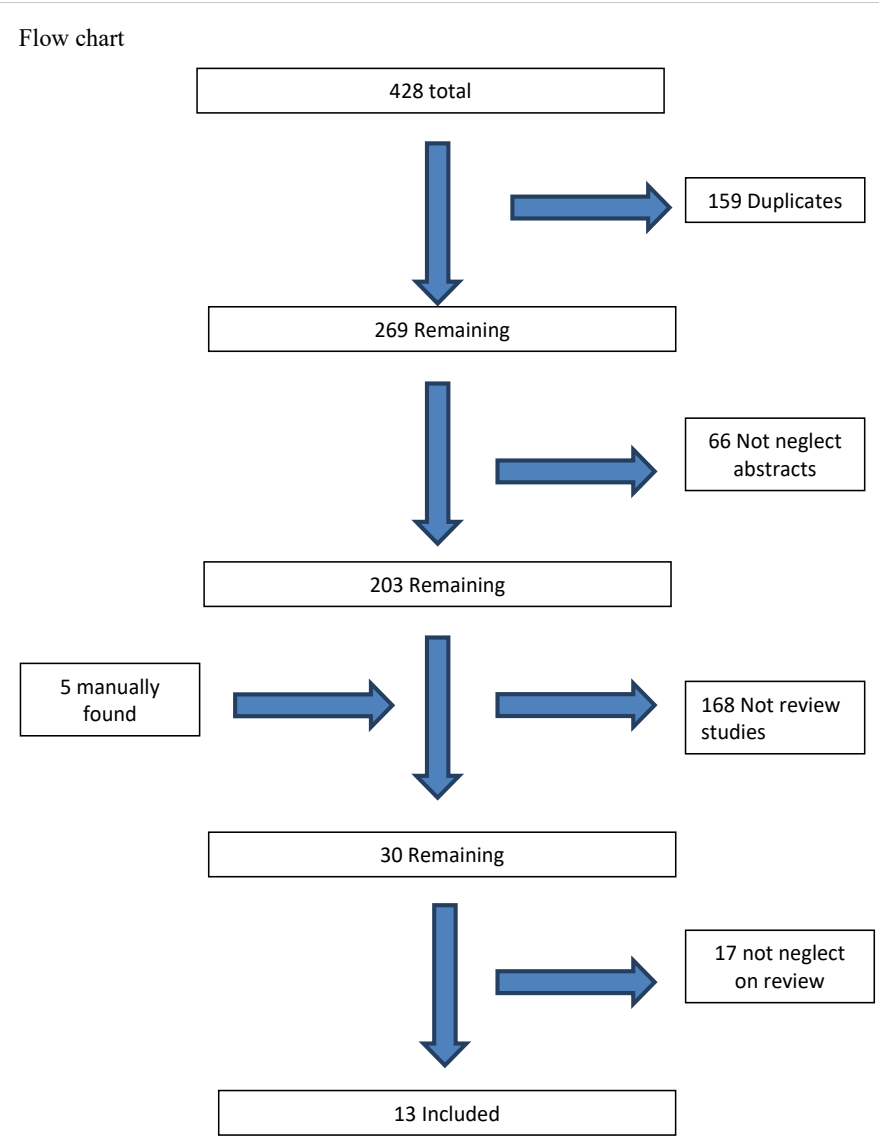

All studies emphasize the importance of defining the concept of neglect carefully and emphasize the importance of explaining the perspective from which the research formulates a study. Most of the studies have used the WHO's definition of neglect as starting point.

"Child abuse or maltreatment constitutes all forms of physical and/or emotional ill-treatment, sexual abuse, neglect or negligent treatment or commercial or other exploitation, resulting in actual or potential harm to the child's health, survival, development or dignity in the context of a relationship of responsibility, trust or power" [12, p 15].

There is consensus on these categories of neglect: physical, emotional, medical, and educational neglect and neglect of psychological health.

\section{A global problem}

The studies in this review showed that child neglect is a global problem and occurs in all countries and societies [13-15] something which is also pointed out by WHO [16]. However, Stoltenborgh and colleagues [17] found that most studies were carried out in North America with 11 studies, 3 in Asia, 2 in Europe and 2 in Australia.

\section{Prevalence}

Prevalence rates were found to be between $16 \%$ [17] and $26 \%$ [13] in normal populations. It was shown in an Australian study that neglect is complex phenomenon [18] and it was found that prevalence of neglect only, was $26,4 \%$; neglect and physical abuse 8,5\%; neglect and sexual abuse $4,5 \%$; neglect and emotional abuse 13,7\%; neglect and sexual abuse, and physical abuse. 1,9\%; neglect, emotional abuse, and physical abuse $27,9 \%$, and neglect, physical abuse, sexual abuse, and emotional abuse $13,0 \%$.

Many of the studies were made by using the Childhood Trauma Questionnaire (CTQ), and those that did use this found higher values of prevalence than if the Adverse Childhood Experiences- Scale (ACE-questionnaire) was used. Fu, et al. [15] found that prevalence of physical neglect measured with CTQ gave 67,2\%, and with ACE 19,5\%. Emotional neglect measured with CTQ found a value of $73,9 \%$ but with ACE $18,3 \%$.

\section{Costs}

Several studies $[6,13,16,18]$ point out that neglect entails economic costs not only to the single individual, but also costs society large amounts of money. The costs at the societal level are measured in the number of Disability Adjusted Life Years, DALYs.

\section{Consequences and relationship with mental illness}

The connection between neglect and mental illness or other behaviours and problems in adulthood is taken up 


\begin{tabular}{|c|c|c|c|c|c|}
\hline 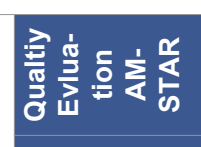 & 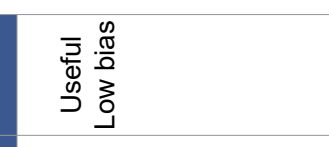 & 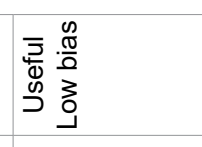 & 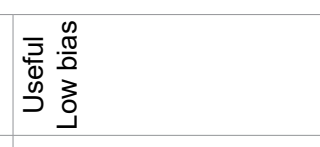 & 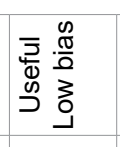 & 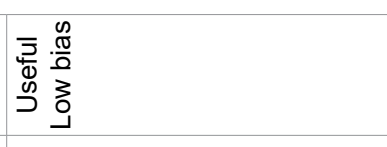 \\
\hline$\frac{\bar{\phi}}{\frac{D}{\alpha}}$ & z & 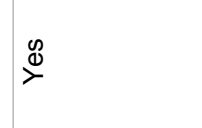 & 2 & 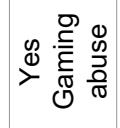 & $\underline{\underline{\sigma}}$ \\
\hline & 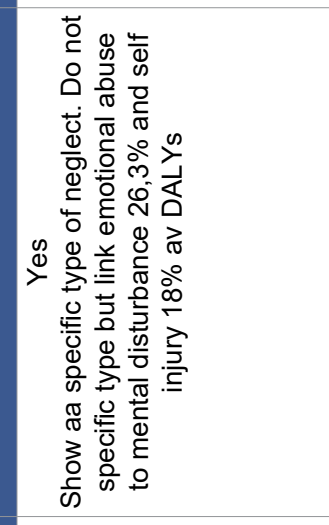 & 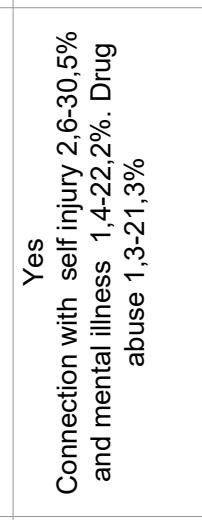 & \& & 을 & 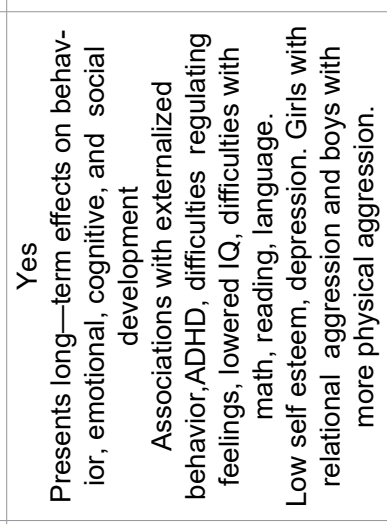 \\
\hline 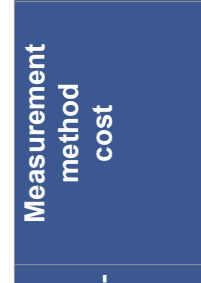 & 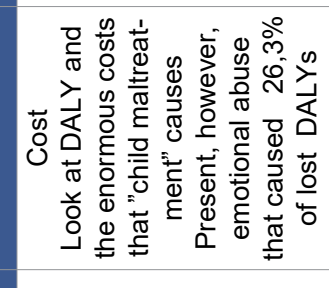 & 0 & 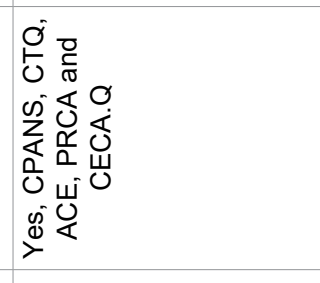 & \& & $x^{\prime}$ \\
\hline 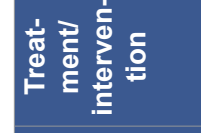 & $\stackrel{2}{2}$ & $\stackrel{\circ}{z}$ & \& & $\stackrel{\circ}{2}$ & $\stackrel{\infty}{\rightleftharpoons}$ \\
\hline غ & $\stackrel{2}{z}$ & $\stackrel{0}{z}$ & ż & $\stackrel{0}{z}$ & $\stackrel{0}{z}$ \\
\hline & 递 & 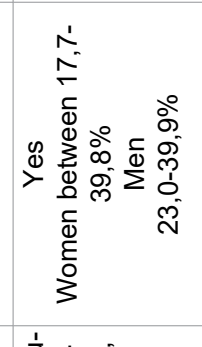 & 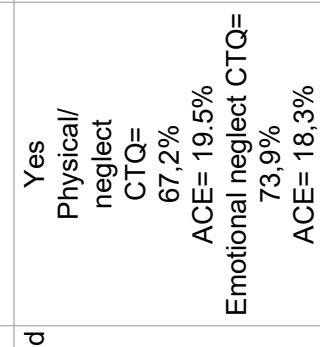 & z & $\stackrel{\circ}{z}$ \\
\hline 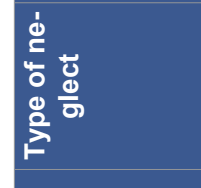 & 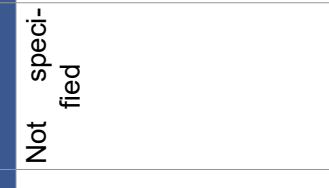 & 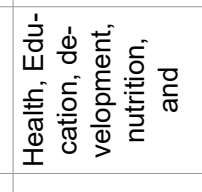 & 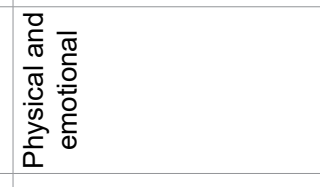 & & 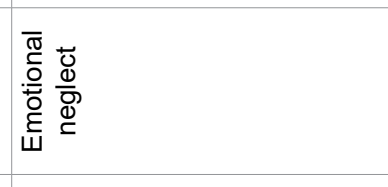 \\
\hline & 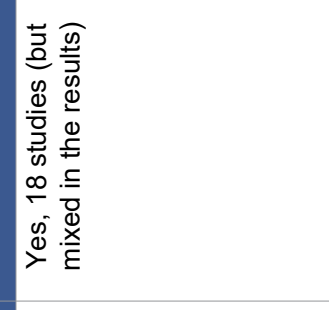 & 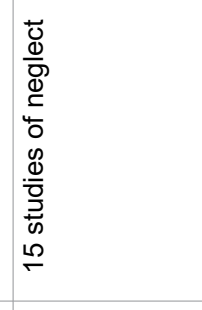 & 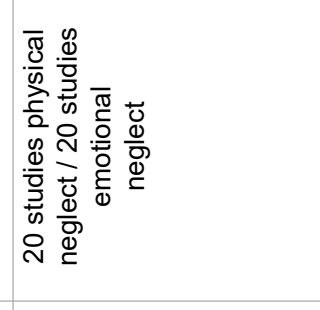 & & 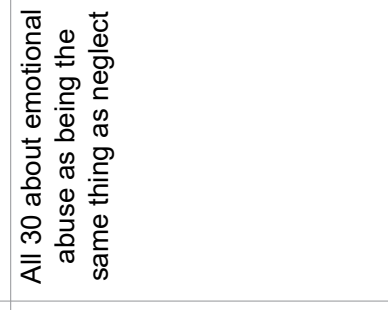 \\
\hline 告 & 产 & 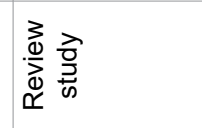 & 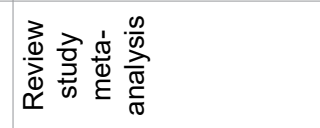 & 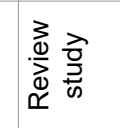 & 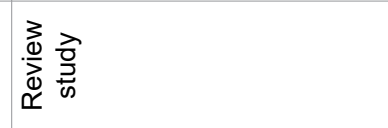 \\
\hline 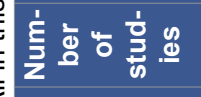 & $\stackrel{\infty}{0}$ & $\stackrel{8}{-}$ & ల్ల & 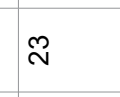 & ஓి \\
\hline 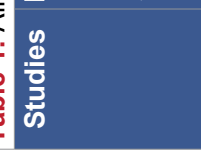 & 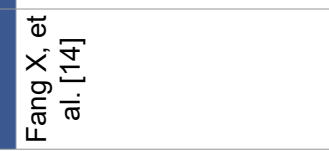 & 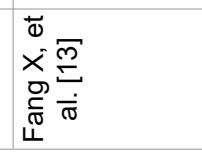 & 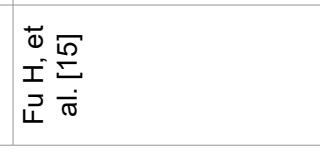 & 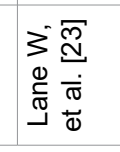 & 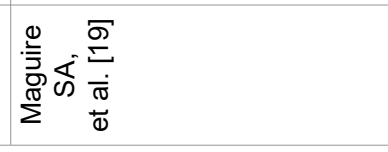 \\
\hline
\end{tabular}




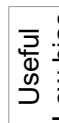

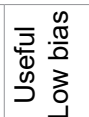

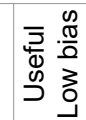

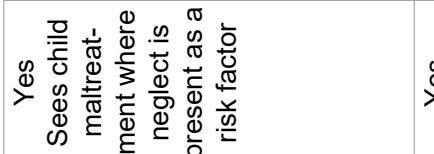

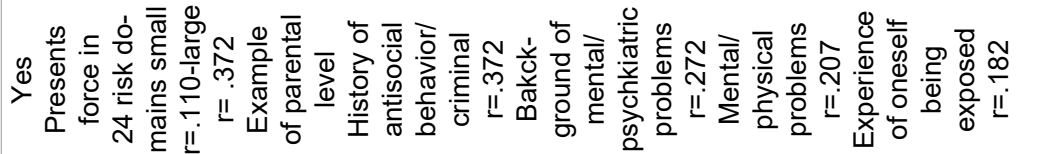

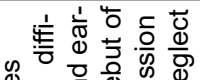

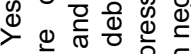

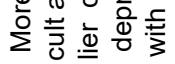

过

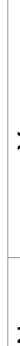

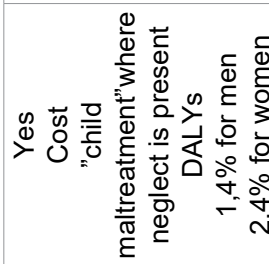

之

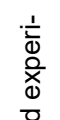

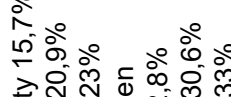

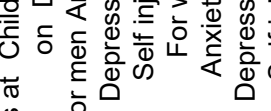

㐫

$\mathscr{8}$

운

象

zे

우

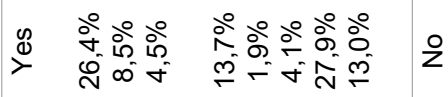

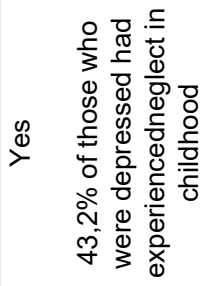

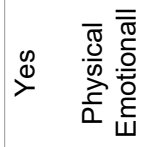

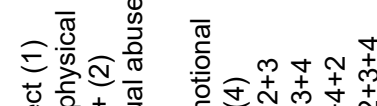

⿻

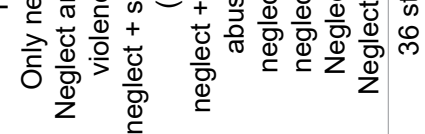

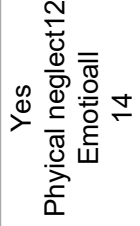

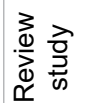

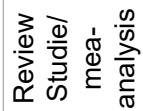

离

œ

ก

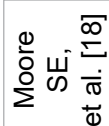

$\stackrel{\infty}{\infty}$

苑

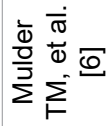

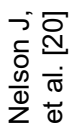




\begin{tabular}{|c|c|c|c|c|}
\hline 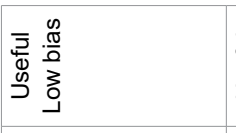 & 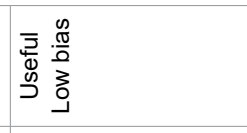 & 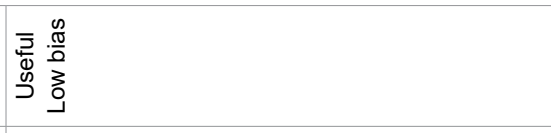 & 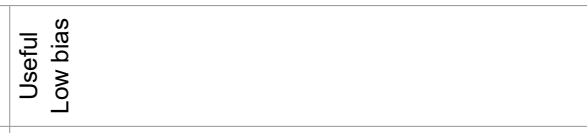 & 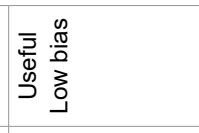 \\
\hline$\stackrel{\infty}{\supset}$ & & $\stackrel{\circ}{z}$ & ì & 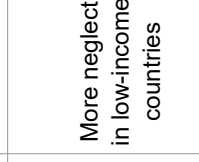 \\
\hline 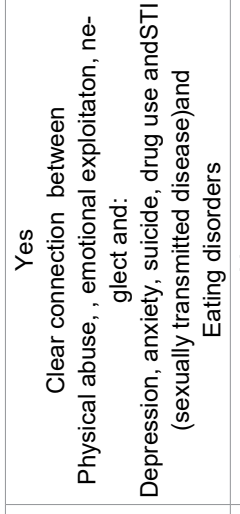 & 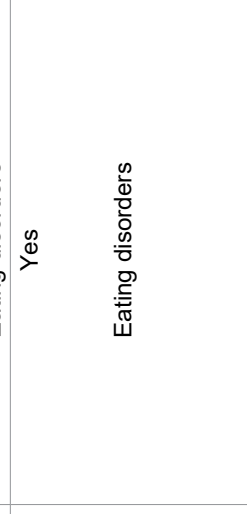 & 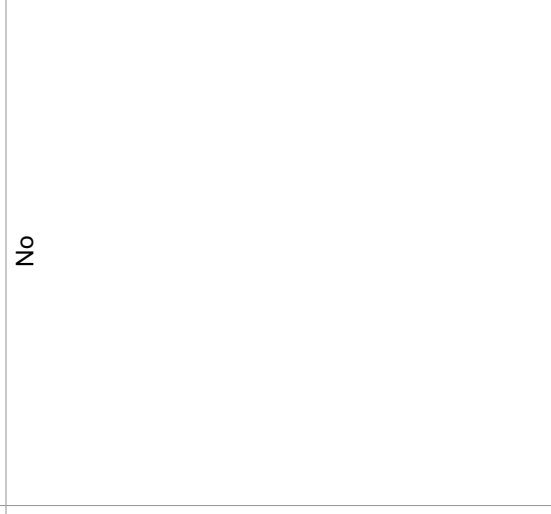 & 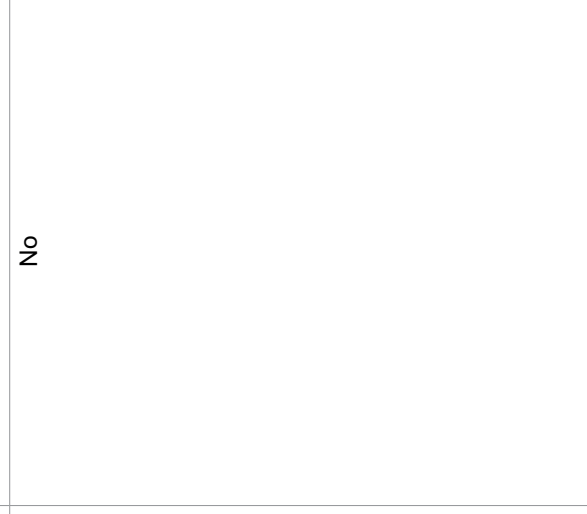 & 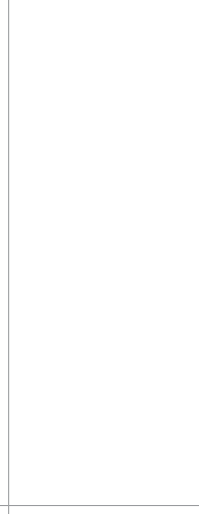 \\
\hline$\stackrel{\circ}{z}$ & $\stackrel{\infty}{\rightleftharpoons}$ & zo & $\stackrel{\circ}{z}$ & 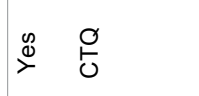 \\
\hline $\bar{z}$ & ㅇ & ’̀ & ㅇ & z \\
\hline z & 울 & zo & 울 & z \\
\hline$\stackrel{0}{z}$ & 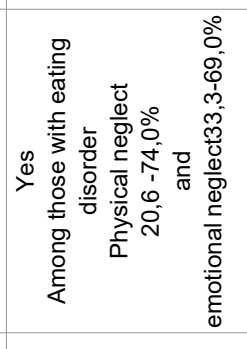 & 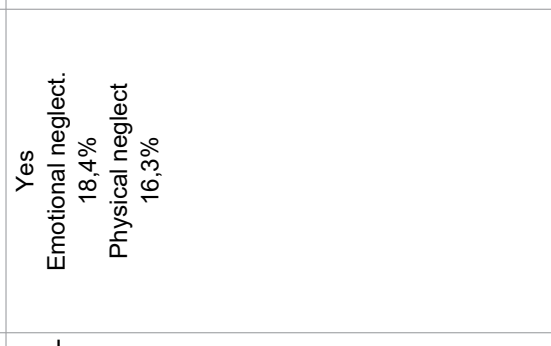 & 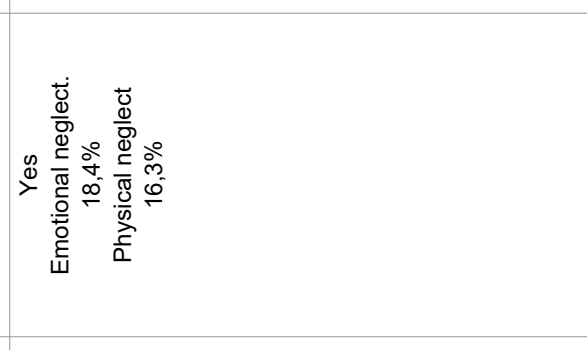 & $\stackrel{\mathscr{D}}{\succ}$ \\
\hline 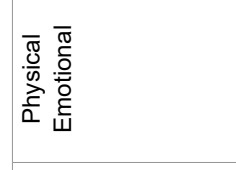 & ) & 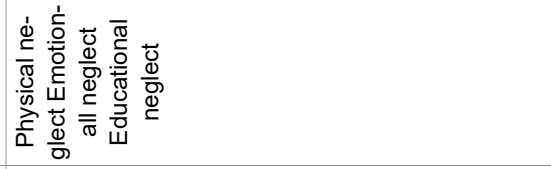 & 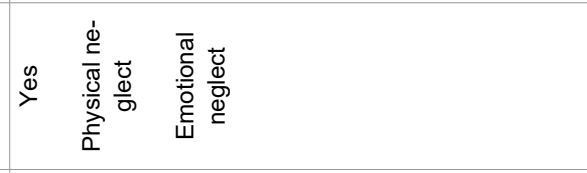 & 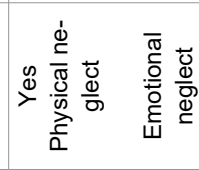 \\
\hline 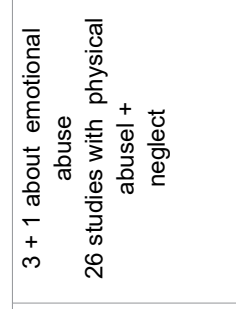 & r & 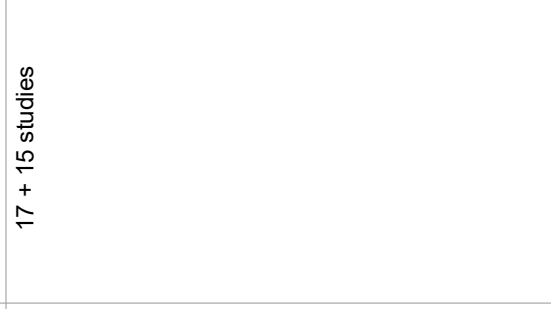 & 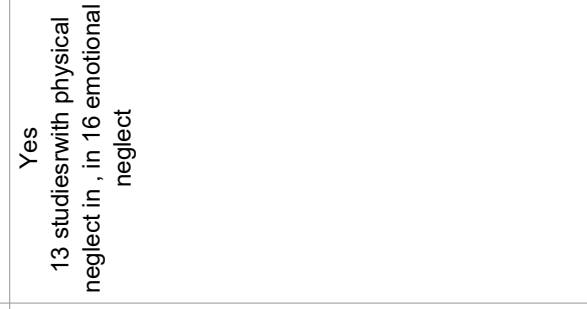 & 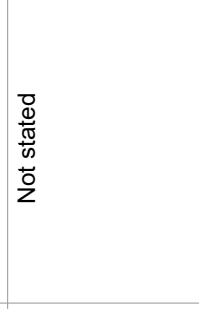 \\
\hline 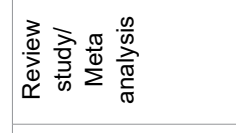 & 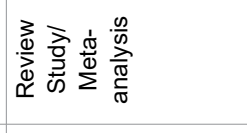 & 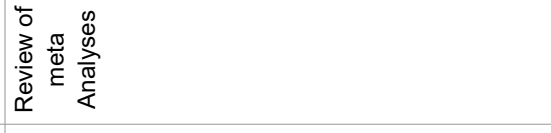 & 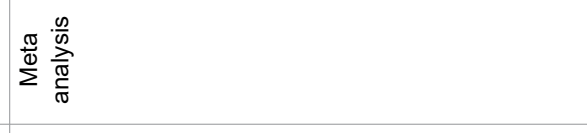 & 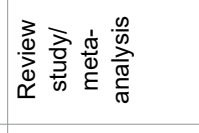 \\
\hline 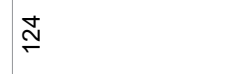 & $\wedge$ & 守 & 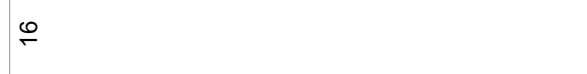 & $\stackrel{\infty}{\infty}$ \\
\hline 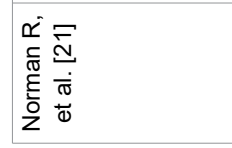 & 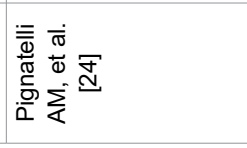 & 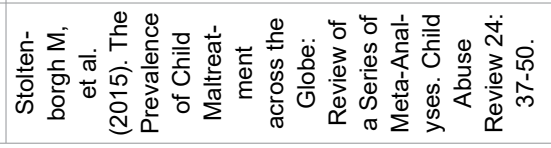 & 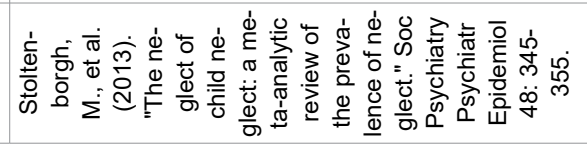 & 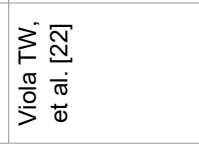 \\
\hline
\end{tabular}


in several of the studies $[14,15,19]$. The reports showed among other things that there are many who have mental illness, drug abuse, or have self-harm behaviour among individuals who have been subjected to neglect compared with individuals who have never experienced neglect $[13,18]$. Several research groups report that there is a definite increase in risk of developing depression as an adult if one has been neglected during childhood $[20,21]$. Those who had been neglected responded less well to treatment than those in a group of depressed individuals who had not been neglected [20]. One review study showed that neglect can result in long lasting effects on the child's emotional, cognitive, and social development [19]. Clear associations were found between neglect and ADHD, lower IQ, reading difficulties, and delayed language development [19]. The earlier the neglect begins in a child's life, the greater the difficulty for the child to control aggression later in life as shown by Maguire and colleagues [19] in their report. Experiencing depression after being neglected has been shown to be related to dose - if the child has been neglected over a longer time there is an increased risk of developing depression later in life [21].

\section{Risk factors}

Risk factors can occur at the societal level, and in this literature, review it was also shown that the factors that involve the parent-child relationship, that is the microsystem, are those that seem to have the greatest importance. This indicates that the largest, and perhaps most serious, part of neglect occurs in the home at the hands of the parents or caregiver [6].

\section{Prevention}

In order take protective measures in an effective manner there is a need to develop instruments for measuring risk factors according to Mulder, et al. [6]. Other research groups call attention to the fact that early interventions that support the parents are effectful and important in protective work $[17,21]$.

\section{Discussion}

In this review of reviews and metanalyses up to 2018 it has clearly been shown that child neglect is a global problem and needs to be taken seriously. The costs of neglect for both the single individual and societies are large counted in DALY's. However, the figures concerning prevalence can vary and it is important for clinicians and researchers to investigate which instruments have been used in the presentation of prevalence. The assessment scale CTQ has been used in many studies and have shown to give much higher prevalence rate than for example the ACE scale [15]. This shows that it is extremely important to recognize this difference when one is concerned with the ability of different measuring instruments to identify problems, and to take this into consideration when one is reading prevalence values $[15,22]$.
Other factors that influence prevalence values depend on the presence of different systems in for example, psychiatry and general health care or if the study group already exists in reports by the police or social services. Prevalence rates have also shown to be different depending on if it is self-report which shows to be higher than if it is professionals who report [17].

The consequences on mental health have also in this review shown to be large [18-21,23,24]. Pigantelli and colleagues [24] found for example that about $50 \%$ of persons with eating disorder reported themselves to have been emotionally neglected as children.

It has been found indications that people who had been neglected in childhood earlier in life develop chronic depression more often than those who are given a diagnosis of depression but who have not been neglected in childhood. In addition, it was shown that the consequences of neglect could be such as low self-regard, periods of depression, and a difficulty in keeping friends, worse record of school attendance and in increased risk and an addiction to computer games [23].

In several studies a connection was found between neglect during childhood and being plagued with anxiety as an adult [18]. The same is true for being afflicted with eating disorder where the risk is 3 times greater for children who have been neglected [24]. Studies have also shown that neglect during childhood increases the risk of having a sexually transmissible illness (STI) later in life [21]. The earlier the neglect begins in a child's life, the greater the difficulty the child will have in controlling aggression later in life as shown by Maguire and colleagues [19] in their report.

Researchers want it understood that it is important to know risk factors in order to be able to understand the aetiology associated with neglect.

Based on the ecological models, it appears that risk factors are found in the microsystem, i.e. in the family, especially in the parents but also in the interaction between children and parents. The risk factors are there, but also the protection factors, and this is an area in which there is unfortunately a lack of research. An important perspective is also how does the focus lie in the specific needs of the child or in the deficiencies of the parents and their failures?

\section{Absence of research and possible distortion in research on neglect}

When it comes to macro, exo and meso systems, more neglect is found in low- and middle-income countries [22]. Thus, it can be said that geographical and economic factors affect the variations in child maltreatment. An example of global differences is access to school. To not be allowed to go to school is to be neglected according to the WHO definition. 
Overall, there is not much research in this area, and few have examined these areas in the research we reviewed.

An additional type of distortion in research, which we named earlier may be that most studies are carried out in countries that are not so densely populated, and there is to a large extent a lack of studies from the African continent (with the exception of South Africa). The majority of studies have been carried out in North America, above all in the USA. Even a study by Viola, et al. [22] shows that there is distortion as concerns where studies are carried out.

\section{Limitations in this review}

This review is a systematic review of the literature and specifically a review based on previous reviews and metaanalyses. As a result, single articles may have been missed depending on the search terms used in the review articles and meta-analyses. Stiths, et al. [25] is a review article that was discovered late in the process when reading Mulders et al. from 2018 [6]. However even if we read Stiths, et al. [25] later no result had to be changed. We have tried to minimize the risk of missing important elements by searching in other summaries of research.

In addition, we found in Fangs, et al. [14] references to several articles that were only published in Chinese that made it impossible for us to read them.

\section{Conclusion and future research}

Neglect is a global problem and the most common and most serious risk factors are present within the family system. It is a higher prevalence in clinical groups and in self-reported studies. There is a link between neglect and health problems in adulthood, especially with depression, anxiety, self-harm and eating disorders. There is a lack of knowledge about neglect in densely populated countries and from the African continent. So future research must explore the situation in those countries.

\section{Acknowledgement}

To Linköping University and the Department of Child and Adolescent Psychiatry and Human development, the National competence centre, Barnafrid who gave us this task.

\section{References}

1. Erickson M, Egeland B. Child neglect. In: Myers J, Berliner L, Briere, J Hendiz C, Jenny C, Reid T, editors. The APSAC handbook on child maltreatment. 2nd Ed. Sage Publications; Thousand Oaks. 2002.

2. Dubowitz $\mathrm{H}$, Bennett $\mathrm{S}$. Physical abuse and neglect of children. Lancet. 2007; 369: 1891-1899.

PubMed: https://pubmed.ncbi.nlm.nih.gov/17544770/

3. Maguire S, Naughton A. Neglect: widespread, damaging and difficult to identify. Paediatrics and Child Health (UK). 2016; 26: 485-487.

4. Woodman J, Lecky F, Hodes D, Pitt M, Taylor B, et al. Screening injured children for physical abuse or neglect in emergency departments: a systematic review. Child Care Health Dev. 2009; 36; 2: 153-164. PubMed: https://pubmed.ncbi.nlm.nih.gov/20047596/
5. Prevoo MJL, StoltenborghM, Alink LRA, Bakermans-Kranenburg MJ, van IJzendoorn MH. Methodological Moderators in Prevalence Studies on Child Maltreatment: Review of a Series of Meta-Analyses. Child Abuse Review. 2017; 26: 141-157.

6. Mulder TM, Kuiper KC, van der Put CE, Stams GJM, Assink M. Risk factors for child neglect: A meta-analytic review. Child Abuse Negl. 2018; 77: 198-210.

PubMed: https://pubmed.ncbi.nlm.nih.gov/29358122/

7. Knight L, Collins K. A 25-year retrospective review of deaths due to pediatric neglect. The American journal of forensic medicine and pathology. 2005; 26: 221-228.

PubMed: https://pubmed.ncbi.nlm.nih.gov/16121076/

8. Kvist T, Cocozza M, Annerbäck EM, Dahllöf G. Child maltreatment prevalence and characteristics of mandatory reports from dental professionals to the Social Services. Int J Paediatr Dent. 2016; 27:3-10. PubMed: https://pubmed.ncbi.nlm.nih.gov/26992159/

9. Naidoo S. A Profile of the Oro-Facial Injuries in Child Physical Abuse at a Children's Hospital. Child Abuse Negl. 2000; 24: 521-534. PubMed: https://pubmed.ncbi.nlm.nih.gov/10798841/

10. Butchard A, Phinney Harvey A, Mian M, Fürniss T. Preventing Child Maltreatment: A guide to taking action and generating evidence. World Health Organization, Geneva, 2006 Geneva/Aurora, CO: WHO. 2006.

11. Shea BJ, Grimshaw JM, Wells GA, Boers M, Andersson N, et al. Development of AMSTAR: a measurement tool to assess the methodological quality of systematic reviews. BMC Med Res Methodol. 2007; 7: 10.

PubMed: https://pubmed.ncbi.nlm.nih.gov/17302989/

12. World Health Organization. Report of the Consultation on Child Abuse Prevention 29-21 March 1999, WHO, Geneva. World Health Organization: Geneva. 1999.

13. Fang X, Fry DA, Brown DS, Mercy JA, Dunne MP, et al. The burden of child maltreatment in the East Asia and Pacific region. Child Abuse and Neglect. 2015; 42: 146-162.

PubMed: https://pubmed.ncbi.nlm.nih.gov/25757367/

14. Fang X, Fry DA, Finkelhor D, Chen J, Lannen P, et al. The burden of child maltreatment in China: a systematic review. Bull World Health Organ. 2015; 93: 176-185c.

PubMed: https://pubmed.ncbi.nlm.nih.gov/25838613/

15. Fu H, Feng $\mathrm{T}$, Qin J, Wanf $\mathrm{T}$, Wu X, et al. Reported prevalence of childhood maltreatment among Chinese college students: A systematic review and meta-analysis. PLoS One. 2018; 13: e0205808.

PubMed: https://pubmed.ncbi.nlm.nih.gov/30321243/

16. World Health Organization. World Health Report 2005: Make every mother and child count. Geneva: WHO, 2005

17. Stoltenborgh $M$, Bakermans-Kranenburg $M J$, van ljzendoorn $\mathrm{MH}$ Alink LR. Cultural-geographical differences in the occurrence of child physical abuse? A meta-analysis of global prevalence. Int J Psychol. 2013; 48: 81-94.

PubMed: https://pubmed.ncbi.nIm.nih.gov/23597008/

18. Moore SE, Scott JG, Ferrari AJ, Mills R, Dunne MP, et al. Burden attributable to child maltreatment in Australia. Child Abuse Negl. 2015; 48: 208-220.

PubMed: https://pubmed.ncbi.nlm.nih.gov/26056058/

19. Maguire SA, Williams B, Naughton A, Cowley L, Tempest V, et al. A systematic review of the emotional, behavioural and cognitive features exhibited by school-aged children experiencing neglect or emotional abuseChild Care Health Dev. 2015; 41: 641-653.

PubMed: https://pubmed.ncbi.nlm.nih.gov/25733080/

20. Nelson J, Klumparndt A, Doebler P, Ehring T. Childhood maltreatment and characteristics of adult depression: Meta-analysis. Br J Psychiatry. 2017; 210: 96-104. https://pubmed.ncbi.nlm.nih.gov/27908895/

21. Norman RE, Byambaa M, De R, Butchart A, Scott J, et al. The Longterm health consequences of child Physical abuse, emotional abuse, 
and neglect: A systematic reiview and meta-analysis. Plos Med. 2012; 9: 11e1001349.

PubMed: https://pubmed.ncbi.nIm.nih.gov/23209385/

22. Viola TW, Salun GA, Kluwe-Schiavon B, Sanvicente-Viera B, Levandowski ML, et al. The influence of geographical and economic factors in estimates of childhood abuse and neglect using the Childhood Trauma Questionnaire: A worldwide meta-regression analysis. Child Abuse Negl. 2016; 51: 1-11.

PubMed: https://pubmed.ncbi.nlm.nih.gov/26704298/

23. Lane W, Sacco P, Downton K, Ludeman E, Levy L, et al. Child maltreatment and problem gambling: A systematic review. Child Abuse Negl. 2016; 58: 24-38.

PubMed: https://pubmed.ncbi.nlm.nih.gov/27337693

24. Pignatelli AM, Wampers M, Loriedo C, Biondi M, Vanderlinden J. Childhood neglect in eating disorders: A systematic review and metaanalysis. J Trauma Dissociation. 2017; 18: 100-115.

PubMed: https://pubmed.ncbi.nlm.nih.gov/27282982/

25. Stith MS, Liu T, Davies C, Boykin EL, Adler MC, et al. Risk factors in child maltreatment: A meta-analytic review of the literature. Aggression and Violent, Behavior. 2009; 14: 13-29. 